\title{
THREATS TO JOURNALISM PROFESSION: NEGOTIATIONS FOR EFFICIENCY AND SAFE PRACTICE
}

\author{
Ekene Godfrey Okafor \\ Department of Mass Communication, \\ Nnamdi Azikiwe University, Awka \\ Anambra State, Nigeria \\ 08068683384 \\ ekeneokar@gmail.com
Ogochukwu Nneka Onyenekwe
Department of Mass Communication,
Nnamdi Azikiwe University,
AwkaAnambra State, Nigeria 08056254326
on.onyenekwe@unizik.edu.ng

\begin{abstract}
Despite a plethora of threats such as funding, violence, ownership etc., challenging Journalism profession; amateurs who engage in the practice, seem to continually pose more threats. Amateurs arguably exacerbate the spread of fake and misleading information, disinformation, misinterpretation of issues, improper delivery of information etc., despite the existence of some environmental threats which tend to be hampering efficiency. The aim of this work is to crusade for efficiency and safe practice of journalism in the face of these threats. This paper further seeks to redefine a journalist; the basic qualities required of practicing journalists; the distinctions between professional journalists and amateurs; other environmental constraints confronting practicing journalists; ways the safety of journalists could be observed, and what roles the relevant bodies and individual journalists are to play in the process. This is in view of the possible impact of media contents on the general public. This paper therefore advocates for efficiency and safe practice of journalism profession devoid of litigations, conflicts, hate messages, ethical or language issues as well as the provision of good work environment for practicing Journalists to boost their productivity. We conclude that existence of amateurs and other environmental constraints should not downplay or discredit the prestige of the profession as a highly disciplined one
\end{abstract}

Keywords: Journalists, Safe practice, Amateurs, Safety, Threats

\section{INTRODUCTION}

Journalism is a disciplined and heavily contested field, with many perspectives. Scholars have documented the recent developments in the field of journalism and its widening scope with prominent strands of thinking, not only around objectivity, professionalism and truthseeking, but encompassing also gatekeeping, agenda-setting, source relations along with ethics, convergence, and reception (Barbie, 2008; Franklin, Hamer, Hanna, Kinsey \& Richardson, 2005). Incidentally, some environmental factors, the Internet era and the influx of social media seem to threaten the practice of journalism. Amateurs, who are armed with knowledge of mobile and digital facilities, often present news and articles online for public consumption notwithstanding a number of other environmental threats which hinder professional journalists from efficiency. New technologies seem to be increasing the threats as anybody with internet access and digital gadgets, can create and share all sorts of messages to others whereas the environmental conditions of the professionals need improvement.

With affordances of mobile technologies and the Internet, argument about possible displacement of old media became widely contested among scholars. Since the first empirical attempts to explore the potential impact of new media on old press in the 1940s, there have 
been two main approaches to the issue: one is centred on the medium and its attributes in support of a displacement and replacement (absolute displacement) argument (Nguyen $\&$ Western, 2006). The other is focused on users' needs and often results in proposing a complementary effect of the new on the old (Lee \& Leung 2004). The first approach has a link with the unprecedented emergence of the Internet as powerful news and information medium, which led to speculations about the death of old media in the face of new communication technologies with keyword phrases 'death of print', 'death of television' 'death of radio', etc. These speculations have received intense attention in both academic and industrial research (Bromley \& Bowles 1995; O'Toole 2000; Kayany\&Yelsma 2000; Lee \& Leung 2004; Dutta-Bergman, 2004).

Majority of these previous studies are based on the medium-centred perspective, which assumes that different media serve the same functions for users so that new media will eventually drive old media out of existence (McCombs 1972). Nguyen and Western (2006) suggest that online news and information usage at different usage levels is positively related with the use of traditional news and information sources, especially those that are more information-intensive. They suggest therefore, an apparent complementary effect of networked sources on traditional ones: despite the apparent 'power' of the Internet in communication and information capacity and quality, receivers of online news and information at different levels still use traditional sources substantially.

In Nigeria, Dunu, Ugbo and Ezepue (2015) studied the media consumption pattern among elites in South-East Nigeria under the framework of the Uses and Gratifications approach, to determine if any similarities as observed in developed countries of the world will prevail in Nigeria. They found that respondents still widely use the traditional media for gratifying their various needs as opposed to the findings in other parts of the globe that suggest a seeming displacement and replacement effect of the traditional media by the new media. Besides these scores of debates and in spite of the various aspects of media convergence occasioned by the Internet and mobile technologies, the central focus of this paper is to reestablish who a journalist is; what stands a practising journalist out among a host of others who package stories for public consumption. As Fernández (2010) submits, Journalism is based on the search of the truth to spread it and transmit it to others and that, whatever the means are chosen, it will remain in force.

\section{WHO IS A JOURNALIST?}

This burning question had raised concerns in recent times. It is often noticed that some persons who have access to online digital facilities and believe they can write, engage in Journalism Profession. Some may not bother to possess the fundamental training and skills that should improve the quality of their job. It is crucial to note that there are necessary foundational requirements and trainings that should improve the output of a professional journalist and also peculiar guidelines such a journalist should observe for more seamless practice. These skills among others include; knowledge of the various media dynamism; uniqueness of the individual media organizations and their house styles; how to safely practice journalism with good morals; without infringement on the fundamental rights of others, without threat to the public and to the culture etc. However, Goldstein (1984 p.175) attempts to draw consensus from the sociologists with a list of professional attributes. He identifies four essential qualities:

(1) A body of esoteric knowledge mastery of which is the indispensable qualification for practice of the profession; 
Volume 1 Number 2

(2) Monopoly - that is, recognition of the exclusive competence of the Job in the domain to which its body of knowledge denotes;

(3) Autonomy, or control including who can legitimately do that work and how the work is done; and

(4) A service ideal - that is a commitment or ethical imperative to place the welfare of the public or the individual client above the self-interest of the practitioner.

Professional Journalists should therefore demonstrate an appreciable competence level, always reporting on facts, not advertising or ideological propaganda.

Meanwhile, Scholars had attempted defining who a journalist is. Some definitions have been contested owing to the complexity and widespread Internet use as well as the art of selfpublishing among both professional journalists and amateurs. For instance, Johnstone, Slawski, \& Bowman, (1976) had described journalists as those whose responsibilities lie in news and information gathering, information processing, and editing, or those who supervise and manage media operations. Journalists are also news-media personnel with editorial responsibility who prepare or transmit information to audience of media organisations (Hanitzsch, \&Hoxha, 2016). Nisbert (2012) had added that journalists are public intellectuals who view the world deductively, immerse themselves in research and offer necessary analysis.

Similarly, Donsbach, (2010) suggests that journalists are professional and detached traders of information (mediators), who pursue subjective goals (communicator) for the sake of public good. He further suggests a redefinition of journalists based on their fields of competence; subject, process, skills and values. Above all the critical role being played by these professionals should not be downplayed. Across all these definitions, we hereby present a definition of a journalist as a good writer, a reporter and editor or a correspondence for a media organization who is trained, very knowledgeable and possess the basic requirements for the job. He or She should be able to produce in-depth, thorough, elaborate, comprehensive, discriminate and very lucid reports of any specific area or field of coverage. In other words, journalism is a profession which requires some level of expertise in writing and speech as well as decency, dignity and high sense of responsibility.

\section{THE QUALIFICATIONS AND QUALITIES OF A JOURNALIST The Qualifications}

We now suggest some essential attributes of a journalist as follows:

$>$ A journalist should possess a university degree or diploma in Mass Communication, Journalism or related disciplines

$>\mathrm{He}$ or she should be accredited or registered with the professional association as the case may be, in the country of practice.

$>\mathrm{He}$ or she must be a good writer, analyst, interviewer, reviewer, speaker, and highly disciplined.

$>\mathrm{He}$ or she must be a versatile reader. 
One of the necessary skills required of a practising journalist is effective writing. He or she should know how to play with words and should be able to produce an error-free, grammatically correct and concise article with factual information.

\section{Research and Knowledge}

Journalists should always engage in research, conduct interviews and always get regularly updated on contemporary issues. The journalist should be versatile in knowledge which is a product of research. Being versatile will enable the journalist report problems objectively and with needed facts and information.

\section{Investigation}

A Professional Journalist should have the ability to investigate facts and obtain needed evidence with which to present issues. He or she should remain vigilant and possess strong analytical skills to assess any troubling or controversial situation. The Journalist should be able to examine a situation critically and present same with sound judgment.

\section{Communication}

A Professional Journalist should be able to maintain good contact with people, especially the sources of information and then use both the verbal and non-verbal communication cues effectively. This skill will enable the Journalist to excel in the profession by breaking the barrier of communication

\section{Self-confidence, Persistence and Discipline}

A journalist should demonstrate self-confidence, always take up responsibilities and should meet up with the deadline. He should be eager to explore new areas and accept constructive criticisms. Indeed, journalism is a highly disciplined profession which requires persistence to satisfy the needs of the audience. This includes all such activities including the hunt for stories, gathering same, editing and processing of the stories in a systematic manner, devoid of legal and ethical problems.

\section{DISTINGUISHING A PROFESSIONAL JOURNALIST FROM AMATEURS}

The Professional Journalist should be distinct from amateurs in two dominant ways:

\section{The Writing of a Professional Journalist}

\section{Ii The Ethical behaviour of a Professional Journalist}

\section{The Writing of a Professional Journalist}

A Professional journalist should demonstrate a mastery of the various journalistic writings and how to gather, process and present accurate reports objectively to the audience. The Professional Journalist should also use the appropriate language, tenses and expressions devoid of grammatical, syntactical and factual errors, omissions or biases. The journalist should also be an expert in any chosen field of Practice. For instance, a Print Journalist should master the intricacies of Print Journalism while a Broadcast Journalist should also have adequate mastery of Broadcast Journalism. Accordingly, Okunna, Omenugha and Ebeze (2002) have explained that broadcast messages are written usually in a conversational style, the informal manner in which a person ordinarily speaks, and, that simple words are used even to the point of oversimplification. They also maintain that print media is the most exciting in terms of word usage where a writer's register of words, utilisation of sentences, clauses and phrase, the deployment of rhythm, and the power of persuasion are most prominent and exciting. According to them, while writing for broadcasting should be done in a layperson's language, which means using familiar words, print media enjoy the latitude and elasticity of verbal usage that tends to bother on poetic exuberance.

Despite the uniqueness and differences between broadcast journalism and print journalism, a practising Journalist should understand the peculiarities of all the various journalistie writings. For instance, writers of news stories do not inject their subjective views. The stories 
are written in the present tense or in the present continuous tense to emphasise newness, otherwise it is no longer 'news'. Editorials and feature articles are usually embellished with the writer's opinions, arguments and could contain analysis of past events but news stories are usually straightforward reports.

Besides, news stories contain some vital ingredients. They include a clear headline, the lead; often containing the basic 5Ws and $\mathrm{H}$ (Who, What, Where, When, Why and How), byline etc. News stories should also include the criteria for newsworthiness (timeliness, proximity, prominence, unusualness or oddity, human interest) etc. On the other hand, 'feature' refers to that form of journalistic writing which is distinct from a news story by going beyond the mere statement of the facts of an event to provide the background, course of development and the implications of the occurrence of an issue to similar activities and process in society; A feature is also written in an exciting and creative manner with information drawn from people involved, eye-witnesses, experts on the subject, and those affected by the issue (Okoro\&Agbo, 2003). It is instructive also to note that all the journalistic writings have their unique peculiarities and should be presented as such to the readers to avoid misconception and biases. Also, Mallette (1996) as cited in Okoro and Agbo (2003), recommended some specific checkpoints for good writing as follows:

$>$ Use of active voice

$>$ Relying heavily on definite nouns and verbs

$>$ Using simple and short words

$>$ Avoiding fad words, buzz words, cliché, and clutter especially in the Lead

Besides, Okunna, Omenugha and Ebeze (2002, p.253) had maintained that to write and communicate effectively; the writer has to:

$>$ Understand the theory and practice of effective communication fully.

$>$ Bear the target audience continually in mind and place himself or her in their shoes.

$>$ Avoid semantic noise which refers to any distortion of the encoded message arising from the meaning of the words or symbols used in putting the news together that could result from poor word choice, wrong use of words, and flamboyant and ambiguous expressions.

$>\mathrm{Be}$ familiar with and respect common elements of style such as accuracy, precision, clarity, originality, vividness, simplicity, coherence, brevity, and good figures of speech and idioms.

$>$ Have a good command of the appropriate vocabulary for the topic being addressed.

$>$ Possess a good knowledge of sentence forms, patterns and common errors in sentence construction and paragraphing.

Unfortunately, most amateurs who engage in Journalism profession seem not to observe this uniqueness. It therefore, becomes imperative to understand that reports should be presented in an orderly manner and achieve the expected aim for its creation. A good story is like a good highway; it provides a smooth ride to the destination (Mallette, 1996 as cited in Okoro\&Agbo, 2003).

\section{The ethical behaviour of a professional journalist}


Ethics, which is related to journalism profession, refers to a set of principles of conduct governing an individual or group (Bowles \& Borden, 2004). In this instance, the individual or group are professional journalists who serve the public. Neher and Sandin (2007) further provided several elements of ethics as follows:

First, ethics is targeted at providing people with a system so that the decisions or judgment/s one make can be justified to others and oneself clearly and objectively;

* Second, ethics is concerned with decisions about actions that can be determined to be right or wrong according to the principles of this method;

* Third, the decisions are about activities in which the actors appear to have a choice; they could have done otherwise;

* And fourth, the decisions are seen as intentional: the persons seemed to know what they were doing and intended to do what they did

Therefore, Ethics is a branch of philosophy which is universal, concerns the conduct or intended decisions of people or approaches to an issue. With the context of Journalism, ethics is defined as a branch of philosophy that assists journalists decide what is right to do by giving them standards by which they can judge actions to be right or wrong, good or bad, responsible or irresponsible (Merril\&Lowensten, 1979). Okunna (1995) has explained that the purpose of ethics in mass communication is to assist journalists in being more moral professionals and in stipulating rules, guidelines, norms and principles that will guide the journalist in making moral decisions, and that these rules and guidance as well as the standards, values and policies usually appear in the form of codes, which are prepared and adopted by the journalists themselves. Even the New NPO (Nigerian Press Organisation) code of ethics, which was formally ratified and adopted in 1998, is a more comprehensive document than the old one and comprises 14 subject heads which answers a wide variety of ethical questions on journalism practice. Among these subjects are; truth; accuracy and fairness; privacy; privilege/non-disclosure; decency; plagiarism; and so on. Besides, Okunna (1995) also insists that codes of ethics at all levels of adoption contain certain principles that are cherished as ethical ideals in the field of journalism in practically all regions of the world In addition to this, practising journalists should demonstrate adequate knowledge of the applicable laws in the field of journalism. Oyakhilomen (2009) succinctly provides some definitions of law as follows:

A set of rules governing human activities;

A rule of action recommended or given by some superior which some inferior are bound to obey;

A general body of rules of conduct, which expresses the will of the ruling class as are established by legislation and such customs and rules of community life as are sanctioned by the government. It also entails the application whereby the body of regulations is secured by the coercive force of the state for the protection, consolation and development of the social relations and the public order, beneficial and desirable for the ruling class. 
These Laws include; the privacy law, the copyright law, the defamation law, the obscene and indecent prohibition laws etc. It is indisputable that knowledge of media law and ethics will guide the Journalist to safely perform his or duties within the acceptable legal and ethical standards. It is on this basis that this text presupposes that practising journalists should remain conversant with both the legal and ethical expectations of them. It is obvious that some professional journalists engage in blogging which they perform in a professional way; this work contends that in spite of other environmental threats, journalism profession should be accorded the needed regard. Activities of amateurs should also not be perceived to have downgraded the integrity of the job as many professionals still measure up to appreciable levels.

\section{CHALLENGES CONFRONTING PRACTISING JOURNALISTS}

\section{Threats by Amateurs}

There appears to be increased threats by amateurs who engage in journalism practice. These amateurs could lack journalism background and training but present information for public consumption. Sometimes, they are armed with web publishing tools, digital technologies and mobile devices. Part of the worries is that the mainstream media, where most trained and professional Journalists are attached, is not the only news and information source for public consumption. In fact, there are many alternative and rapidly evolving information sources especially blogs, portals and social media where amateurs publish and share information. Bowman and Willis (2003) had emphasized that the venerable Journalism profession finds itself where its hegemony as gatekeeper of news and information is threatened not only by new technologies and competitors but, also by the audience it serves. These make the amateurs potent in information creation and dissemination. With regard to these, Newman (2009) established that social media and user-generated content change the nature of breaking news and contributes to the compression of the "news cycle", thereby releasing pressure on editors over what and when to report. Therefore, with the increasing Internet and other information technologies, amateurs are enabled to share information to receivers who could become vulnerable to both disinformation, misinformation etc. Consequently, Vanderwagen (2014) had also confirmed a shift in ways journalists source and share information as a result of the challenges posed by the new media. The new media are basically where amateurs operate. This way, normative principles of fairness and accuracy required by professional journalists get endangered by excessive information from less credible sources pushed out by amateurs.

\section{Violence}

Torture, beating, death and expulsion from duty have remained peculiar challenges being confronted by practising journalists who are perceived to have dissenting opinions. Stories surrounding these incidents abound in recent times among practitioners. Amidst these conflicting situations, practising journalists are encouraged to fundamentally uphold ethics and discharge their duties much responsibly.

\section{Funding and Ownership}

The nature of ownership of any media organisation determines to a great extent whether the organisation is dynamic, vigorous, responsive, and responsible or an emasculated, timid, spineless, ineffectual or irresponsible press (Okoro\&Agbo, 2003). As an effect of ownership, most media organisations conform to peculiar housestyles and editorial policies. Apart from the nature of ownership, inadequate funding of the industry constitutes a fundamental 
challenge to media professionals which affects their practice. In Nigeria, three main categories of media ownership exist, which include: Government Ownership, Private Ownership and Mixed Ownership. In an instance of corrupt government, Journalists who work for the government could deliberately dish out unbelievable falsehoods without recourse to conscience and chant praises for government programmes that fail to address the problems of the people at the grassroots.

\section{Institutional Bureaucracy}

Media professionals, especially during elections, get encumbered by public demands for the dissemination of political information, especially campaigns which are sometimes full of propaganda and ridicule of opponents. The demand by both the government and nongovernmental institutions on these media organisations to set agenda and disseminate information appears enormous. This can affect the credibility of the organisation. Apart from agenda setting, it is obvious that the media also confer status and legitimacy on political leaders and issues. Okunna and Omenugha (2012) had also explained that the media could enhance or uplift the status of a political candidate in the following ways.

$>$ the media can give more massive headlines to the favoured candidate;

$>$ the press can feature more lead stories on the candidate;

$>$ the press can print more prominent quotations from the candidates' speech;

$>$ photographs and other prominence-enhancing strategies can accompany stories on the candidate;

$>$ the press can publish more remarks praising the candidate

\section{WAYS TO SURMOUNT SOME OF THE THREATS IN JOURNALISM PROFESSION}

\section{Training Programmes}

Practising Journalists should be regularly updated on dynamic changes in the industry and be very conversant with use of online digital facilities. This can be achieved through training programs in the form of conferences, seminars, workshops and other forms of on-the-job trainings on various aspects of the profession. In recent times, traditional or mainstream media have online versions of their dailies or broadcasts which require some technical knowledge for efficiency. Some media organisations also create social media 'pages' where users can follow and get updates on news and information. Given these changes, practising Journalists should always be trained on the dynamics of digital technologies to be able to maintain and embrace the online atmosphere.

\section{Modern Digital Gadgets}

Procurement for these Journalists, very functional and modern digital gadgets will inevitably boost their quality of service. Some digital cameras, microphones, consule, vision mixers etc. produce more quality output and are amenable to non-linear editing and enhanced content, unlike some old-fashioned devices. It is therefore critical for practising Journalists to possess the essential and updated facilities.

\section{Safe Practice}

Safety is vital for both practising journalists and their institutions. There should also be an appreciable level of expertise and work environment upon which the Journalists may operate Any intending practitioner should measure up to an acceptable level and be examined by 
relevant bodies before being allowed to operate. To a reasonable extent, avoidance of defamatory or provocative language by professionals, which is part of the mastery of journalism, is recommended.Also, provision or acquisition of essential facilities by the practising journalists is also imperative.

Besides, these journalists and their sources are sometimes victims of attacks. Criminal organizations, authorities, activists, and citizens often attack journalists and media outlets which results in severe consequences. In the worst case, journalists and sources get killed and essential news stories silenced.

Brennan (2018) then introduced the three-dimensional concept of new safety which suggests a blend of safety and news, the interrelated actors involved in sustaining security for journalism and the information processing, as well as actions that could enable security in infrastructures. The three sub-dimensions of the concept are; 1) Safety and infrastructures, 2) Safety in practice and 3) Safety and its consequences.

It can be understood that the first dimension emphasises how news media and their actors develop and use the necessary infrastructures (platforms, systems and tools etc), to improve safety issues applicable to the protection of self, story, journalists' role, as well as their sources.

The second dimension revolves around the knowledge of Journalists about safety and how they should engage in research to improve their knowledge level about safety in journalism practice.

The third dimension highlights the different kinds of effects that emanate as a result of threats to the safety of journalists, how such constitute societal problems and how they could be managed.

\section{IMPROVING THE ENVIRONMENTAL CONDITIONS OF PRACTISING JOURNALISTS}

\section{Remuneration}

There is a need for an upward review of the salaries being paid to Journalists in both the private and government-owned organisations, and also be motivated especially those who demonstrate commitment and loyalty towards their job. These Journalists should always be rewarded to encourage proficiency and service delivery among them

They should also not be relieved of their duties arbitrarily often without terminal benefits or entitlements. They should be protected and encouraged to always stand on the truth.

\section{Special Allowances}

This text recommends that practisingjournalists receive work-related allowances, especially for hazards. There should be special considerations for investigative journalists who risk their lives. Similarly, those who report on rural communities with poor access roads and other hindrances are also to receive these allowances. These provisions can give practising journalists a sense of belonging.

\section{Role of Government Institutions}


$>$ The government institutions should protect Journalists at all times and should demonstrate absolute regard and support for them.

$>$ The government institutions could set up an independent body that could protect the rights of practicing Journalists.

\section{Role of Individual Journalists}

$>$ Journalists should desist from false or fake news reports.

$>$ Journalists should demonstrate good moral.

$>$ Journalists should demonstrate the responsibility of verifying, proofreading and editing the contents they wish to push out for public consumption.

$>$ Journalists should always update themselves on the changing dynamics of the profession.

$>$ Journalists should desist from hate messages, propaganda and provocative contents aimed to defame or ridicule the character of people.

$>$ Journalists should present reports devoid of sensationalism, mockery, satire, or exaggeration.

$>$ Journalists should avoid reports that can attract legal problems but should practice their profession in the best acceptable and honourable way.

\section{Role of Relevant Bodies}

> Nigerian Union of Journalists (NUJ) and other affiliated international, local and regional bodies should set boundaries for safe practice of Journalism and ensure that journalists comply with the directives.

\section{CONCLUSION}

This text concludes that aspiring journalism practitioners should endeavour to equip themselves with the fundamental requirements needed for safe and more efficient practice. Besides, existence of amateurs and other environmental challenges should not downplay or discredit the journalism profession and its integrity. There is the certainty that most practising journalists are proficient and religiously observe the fundamental requirements of the profession. This work further concludes that Journalism profession requires some appreciable level of expertise even in the face of the threats. Therefore, the foundational requirements, morals and integrity of the profession remain essential for efficiency, and journalists should practice safely and responsibly.

\section{REFERENCES}

Barbie, Z. (2008). Journalism and the Academy.In Wahl-Jorgensen, K. and Hanitzsch, T. (eds.) (2008).The handbook of Journalism Studies. New York: Routledge. https://www.routledgehandbooks.com/doi/10.4324/9780203877685.ch3

Bowles, D. \& Borden, D. (2004).Creative Editing. ( $4^{\text {th }}$ ed). Belmont: Thomas Wadsworth

Bowman, S., \& Willis, C. (2003).We Media: How Audiences are Shaping the Future of News and Information. A Seminal Report. Reston: The Media Centre at the American Press Institute. https://goo.gl/WSjaZc.

Bromley, R. \& Bowles, D. (1995).Impact of Internet on use of traditional news media. Newspaper Research Journal, 16(2), 14-27. 
Volume 1 Number 2

Brennan, B. (2018). Journalism Practice: Special Issue on News Safety, Infrastructure, Practice and Consequences. Journalism Practice.(pp 1-10) Marquette university, Wisconsin: Routledge, Taylor \& Francis Group. https://think.taylorandfrancis.com.

Donsbach, W. (2010). Journalists and their professional identities. In S. A. (ed.), Companion to News and Journalism (p. 38-49). London and New York: Routledge.

Dunu, I. V., Ugboh, G. O. \& Ezepue E. (2015). Displacement or complementary effect? An assessment of traditional and New Media use patterns among elites in South-East, Nigeria. Higher Education of Social Science, 8(4), 8-18.

Dutta-Bergman, M. (2004). Complementarity in consumption of news types qcross traditional and New Media. Journal of Broadcasting and Electronic Media, 48(1), 4161.

Fernández, M. A. (2010). A profession termed "Journalism" In Fernández, M. A. (2010).

(ed) Revista Latina de Comunicacion Social.La Laguna (Tenerife, Canary Islands), Spain (pp1-12). http://www.revistalatinacs.org/10/art/879.

Franklin, B., Hamer, M., Hanna, M., Kinsey, M. \&Richardson, J.E. (2005). Key concepts in journalism studies (1st ed.). London: Sage.

Goldstein, J. (1984). Foucault Among the Sociologists: The 'disciplines' and the history of the Profession. History and Theory, XVIII, 170-192

Hanitzsch, T. \&Hoxha, A. (2016).INFOCORE Definitions: “Journalists”. Ludwig Maximilian University-

Munich, Germany.http://www.infocore.eu/results/definitions

Johnstone, J. W. C., Slawski, E. J. \& Bowman, W. W. (1976).The News People: A Sociological Portrait of American Journalists and Their Work. Chicago: University of Illinois Press.

Kayany, J. \&Yelsma, P. (2000). Displacement effects of online media in the sociotechnical contexts of households. Journal of Broadcasting and Electronic Media, 44(2), 215229.

Lee, P. \& Leung, L. (2004).Assessing the displacement effects of the Internet. Paper presented at the International Conference on Internet Communication in Intelligent Societies. School of Journalism \& Communication, Chinese University of Hong Kong, July 8-10.

Mallette, M. (1996). Writing a Process. In Mallette, M. (1996) (ed) Handbook for African Journalists (pp1-15). World Press Freedom Committee: USA

McCombs, M. (1972).Mass media in the marketplace. Thousand Oaks, CA: Sage Publications. https://www.aejmc.org

Merrill, J. C. \& Lowenstein, R. L. (1979).Media, messages and men. New York: Longman 
Volume 1 Number 2

Neher, W. W. \&Sandin, P. J. (2007).Communicating ethically: Character, duties, consequences, and relationships. Boston: Pearson Education Limited

Newman, N. (2009). The Rise of Social Media and Its Impact on Mainstream Journalism. Reuters Institute for the Study of Journalism: Working Papers. University of Oxford: United Kingdom. https://ora.ox.ac.uk/objects.

Nguyen, A. \& Western M. (2006). The complementary relationship between the Internet and traditional mass media: The case of online news and information. Information Research.11(3), pp1-23. https://www. semanticscholar.org

Nisbet, M. C. (2012). Nature's Prophet: Bill McKibben as Journalist, Public Intellectual and Activist. In Joan Shorenstein Center (2013).Discussion Paper Series on the Press, PolicticsAnd Public Policy. School of Communication and the Centre for Social

Media: American University.https://shorensteincenter.org/wp-content/uploads/2013/03/D-78Nisbet1.pdf

Okoro, N. \& Agbo, B. (2003).Writing for the media society.Nsukka: Prize Publishers.

Okunna C. S. (1995). Ethics of Mass Communication (2nd ed.). Enugu: New Generation Books.

Okunna, C. S. \& Omenugha, K. A. (2012).Introduction to Mass Communication $\left(3^{\text {rd }} \mathrm{Ed}\right)$. Enugu: New Generation Books.

Okunna, C. S, Omenugha, K. A. \& Ebeze, V. U. (2002). Writing for the mass media. In C. S.Okunna (Ed.), Teaching mass communication: A multi-dimensional approach (pp. 233-244). Enugu: New Generation Books.

O'Toole, K. (2000). Study offers early look at how Internet is changing daily life. Stanford News Service.https://www.stanford.edu/dept /news/pr/00/000216internet.html.

Oyakhilomen, G. I. (2009). Introduction to law: Kaduna: National Open University of Nigeria.

Vanderwagen, C. (2014). The effects of new media on print magazine in South Africa: An Examination of the Case Study of Rooi Rose Magazine's strategy to encourage user engagement online. An unpublished thesis submitted to the Faculty of Humanities, University of the Witwatersrand, South Africa. 